\title{
FEMINISMO E DISCURSO DE GÊNERO EM REDES SOCIAIS: EMPODERAMENTO FEMININO?
}

\author{
FEMINISM AND GENDER SPEECH IN SOCIAL NETWORKS: FEMALE \\ EMPOWERMENT?
}

\author{
Maria Cecilia Baini ${ }^{1}$, Adail Sobral ${ }^{2}$ \\ ${ }^{1}$ Universidade Católica de Pelotas, Departamento de Letras, Brasil, e-mail: mariabaini@gmail.com \\ 'Universidade Federal de Pelotas, Departamento de Comunicação Brasil, e-mail: \\ sobral.adail@gmail.com
}

\author{
ARTICLE INFO \\ Article history: \\ Received 2020-01-27 \\ Accepted 2020-02-20 \\ Available online $2020-06-20$
}

\begin{abstract}
Palavras-chave: Mulher-Maravilha. Feminismo e empoderamento feminino. Comunicação Mediada pelo Computador, Análise de Discurso Mediada pelo Computador. Keywords: Wonder Woman. feminism. female empowerment. computer mediated communication. Facebook. Computer Mediated Analysis Discourse.
\end{abstract}

RESUMO. Neste estudo analisamos parte da discussão nos sites de redes sociais sobre as questões de gênero em torno do lançamento do filme Mulher-Maravilha, em quatro publicações na página de Facebook oficial da obra. Investigamos, nos comentários sobre o lançamento do filme, a presença de debate sobre as questões feministas, a fim de identificar os temas discutidos e sua perspectiva. A hipótese do trabalho original, a dissertação de mestrado de Maria Cecilia Baini, foi de que o filme iria mobilizar discursos sobre empoderamento feminino. Partindo das discussões sobre questões de gênero a partir dos anos 1930, apresentamos estudos de gênero tal como entendidos hoje e discorremos sobre a presença do feminismo na Internet. Questões sobre poder e discurso são trazidas à tona ancoradas nos preceitos de Bourdieu (1996) e Foucault (2013), a fim de pensar a produção do discurso como resultado de relações de poder na sociedade. A linguagem é entendida, recorrendo-se ao conceito de habitus (BOURDIEU 1989), como passível de naturalizar o poder e como um instrumento que pode estar a serviço da perpetuação da desigualdade dos gêneros. Recorremos a Recuero (2012, 2014) para descrever a comunicação mediada por computador, em seus aspectos relevantes para nossa análise, compreendendo-a como um produto social capaz de simular elementos da conversação oral. Seguindo Herring, (2001, 2004), vemos a comunicação textual como parte dos discursos que vêm a construir comportamentos, recorrendo aos aportes teóricos e metodológicos da Análise do Discurso Mediada por Computador, desenvolvidos por Hering, a fim de tentar identificar padrões recorrentes do discurso examinado, com ênfase nos vinculados à discussão sobre o empoderamento feminino.

ABSTRACT. In this study we analyzed part of the discussion on social networking sites about gender issues
around the release of the film Wonder Woman, in four publications on the official Facebook page of the movie.
We investigated, in the comments on the film's launching, the presence of debates on feminist issues, in order
to identify the topics discussed and their perspective. The hypothesis of the original work, Maria Cecilia Baini's
master's dissertation, was that the film would mobilize discourses on female empowerment. Starting from the
discussions on gender issues from the 1930s, we present gender studies as understood today and discuss the
presence of feminism on the Internet. Questions about power and discourse are based in the precepts of
Bourdieu (1996) and Foucault (2013) in order to think the production of discourse as a result of power relations
in society. Language is understood, by resorting to the concept of habitus (BOURDIEU 1989), as being capable
of naturalizing power and as an instrument that may serve the perpetuation of gender inequality. We have
recourse to Recuero (2012, 2014) to describe computer mediated communication in its aspects relevant to our
analysis, understanding it as a social product capable of simulating elements of oral conversation. To Herring, 
(2001, 2004), textual communication is part of discourses that construct behaviors. Using the theoretical and methodological contributions of the Computer-Mediated Discourse Analysis - developed by Hering - we identified recurrent patterns of discourse, with an emphasis on those linked to the discussion on female empowerment.

\section{Introdução}

Com o advento das tecnologias da informação e com a apropriação dos espaços dos sites de redes sociais, a temática do feminismo vem ganhando força e tem sido amplamente discutida. Neste estudo analisamos, a discussão nos sites de redes sociais sobre as questões de gênero, no que se refere ao lançamento do filme Mulher-Maravilha, em quatro publicações na página de Facebook oficial da obra. Investigamos, nos comentários sobre o lançamento do filme, a presença de debate sobre as questões feministas, a fim de identificar os temas discutidos. Nossa hipótese era de que o filme fosse capaz de mobilizar discursos sobre empoderamento feminino.

\section{O Feminismo e a Internet}

O feminismo como movimento social é, segundo Costa (2013), um movimento moderno que surge no contexto das ideias iluministas e das ideias transformadoras da Revolução Francesa e Americana e se volta, em um primeiro momento, para uma demanda por direitos sociais e políticos. A chamada primeira onda do feminismo (PINTO, 2010) se iniciou nas últimas décadas do século XIX, quando as mulheres, primeiro na Inglaterra, se organizaram para lutar por seus direitos, e que o primeiro se popularizou foi o direito ao voto. As sufragistas, como ficaram conhecidas, promoveram grandes manifestações em Londres. Também no Brasil a primeira onda do feminismo se manifestou mais publicamente por meio da luta pelo voto (PINTO, 2010). As sufragistas brasileiras foram lideradas por Bertha Lutz, bióloga, cientista de importância, que estudou no exterior e voltou para o Brasil na década de 1910, iniciando a luta pelo voto.

Este feminismo inicial, tanto na Europa e nos Estados Unidos como no Brasil, perde força a partir da década de 1930 e só volta a ter importância, na década de 1960, na chamada segunda onda do feminismo. A década de 1960 teve no país uma dinâmica diversa daquela do resto do mundo. Nos primeiros anos, houve grande efervescência: a música revolucionava com a Bossa Nova; Jânio Quadros, após uma vitória avassaladora, renunciava; e Jango chegava ao poder, aceitando o parlamentarismo, a fim de evitar um golpe de estado. $\mathrm{O}$ ano de 1963 foi de radicalizações: de um lado, a esquerda partidária, os estudantes e o próprio governo; de outro, os militares, o governo norte-americano e uma classe média assustada. 
Em 1964, veio o golpe militar, moderado no seu início, mas que se tornaria, no ano de 1968, por meio do Ato Institucional n. 5 (AI-5), que transformava o Presidente da República em um ditador (PINTO, 2010), uma ditadura militar rigorosa. Nesse contexto, muitos movimentos populares, como o movimento feminista, foram silenciados (COSTA, 2013). De acordo com Costa (2013), os anos 1980 trouxeram novos dilemas ao movimento feminista brasileiro, que entra em uma fase de grande efervescência na luta pelos direitos das mulheres: há inúmeros grupos e coletivos em todas as regiões tratando de temas, como violência, sexualidade, direito ao trabalho, igualdade no casamento, direito à terra, direito à saúde materno-infantil, luta contra o racismo, opções sexuais etc. (PINTO, 2010). Como afirma Costa (2013), o avanço do movimento nesse período fez do eleitorado feminino um alvo de interesse de políticos, que começaram a incorporar as demandas das mulheres aos seus programas e plataformas eleitorais e a criar Departamentos Femininos dentro de suas estruturas partidárias. $O$ movimento feminista brasileiro, como movimento social, extrapolou os limites do seu status e do próprio conceito (COSTA, 2013). Foi além da demanda e da pressão política na defesa de seus interesses específicos; entrou no Estado, interagiu com ele e, ao mesmo tempo, conseguiu permanecer autônomo.

O movimento feminista encontrou hoje, no ambiente digital da Internet e dos sites de redes sociais, um contexto de certo modo democrático para ampliar a discussão sobre o empoderamento feminino. Os discursos de gênero passam a ter mais impacto e encontram um espaço de questionamento, confrontando discursos de poder e hegemônicos. A comunicação midiática tem, assim, importante papel na articulação do discurso de gênero, uma vez que o tema do empoderamento feminino passa a ser amplamente discutido nos sites de redes sociais.

\section{Discurso e Poder}

De acordo com Viana (2009), linguagem são os recursos simbólicos utilizados na comunicação humana, isto é, os recursos gráficos e sonoros utilizados para se realizar a comunicação entre os seres humanos. A linguagem, devido a seu caráter social, está submetida ao processo social, possuindo, portanto, a mesma dinâmica, historicidade e singularidade da sociedade onde emerge. Ela acaba tendo, naturalmente, uma formação semelhante ao da sociedade existente, em determinada época e com determinadas relações sociais (VIANA, 2009). Bourdieu (1996) diz que se pode conferir à linguagem uma eficácia simbólica de construção da realidade porque ela estrutura a percepção que os atores sociais têm do mundo, e o modo como eles se relacionam nesse mundo. Nesse sentido, a língua pode ser compreendida como um sistema simbólico que constitui instrumentos de 
conhecimento e de comunicação, e, portanto, de construção de visões de mundo, de percepção do mundo social. Assim, a linguagem não é somente um instrumento de comunicação ou de conhecimento, mas um instrumento de poder (BOURDIEU \& MICELI, 1974).

Através do exercício da linguagem, o convívio social se processa, atrelado à nossa cultura, que é patriarcal, ou seja, apresenta-se sob as normas morais e sociais que os homens impõem às mulheres. No exercício de funções patriarcais, os homens detêm o poder de determinar a conduta das categorias sociais, recebendo autorização ou tolerância da sociedade para punir o que lhes parecer desvio (SAFFIOTI, 2001). A força da ordem masculina pode ser aferida pelo fato de que ela não precisa de justificação: a visão androcêntrica se impõe como neutra e não tem necessidade de se enunciar com vistas à sua legitimação. Bourdieu (1996) propõe que o poder das palavras não está nas palavras em si, mas na legitimidade que Ihes é conferida pelos que falam e pelos que escutam. Nessa perspectiva, ele destaca que o poder da palavra é o poder de mobilizar a autoridade acumulada pelo falante e concentrá-la num ato linguístico. O autor salienta ainda que a linguagem, entendida como discurso, dito e modo de dizer, é, portanto, mecanismo de poder simbólico de construção da realidade, tendendo a servir para estabelecer uma ordem de conhecimento e apreensão, e, assim, uma visão de mundo.

No que se refere ao discurso, Foucault (2013) afirma que se trata de uma rede que se conecta a outras tantas redes de outros discursos, em um sistema aberto, e que registra, estabelece e reproduz valores de uma sociedade que devem ser perpetuados. O discurso, segundo ele, não é um encadeamento lógico de palavras e frases que pretendem ter um significado em si mesmo, mas uma importante organização funcional em que se estrutura um imaginário social. Um discurso é então, para o autor, o encadeamento de significantes que remete a outros discursos externos a ele. Não possui foco no significado e sim no significante e, portanto, no imaginário dos receptores. Reproduz "de" e "para" esse imaginário, consolidando a função de perpetuar leis, regras, normas e valores implícitos socialmente aceitos como "o verdadeiro".

Para Domingos (2015), "esse poder do discurso de instituir 'verdades' leva a se repensar a relação do homem com a verdade, com o verdadeiro de sua época" (p. 19). E, assim, como disse Foucault, cada sociedade tem seu próprio regime de verdades. Trata-se de um sistema ancorado naqueles tipos de discursos que funcionam como verdadeiros em detrimento de discursos tidos como falsos. Assim, por meio dos discursos supostamente verdadeiros, constitui-se toda a cultura de uma época. É uma construção complexa, pois traz em si modos de separação e exclusão ao naturalizar determinadas práticas (DOMINGOS, 2015), havendo neste discurso verdadeiro uma interdependência com o desejo e com o poder 
(FOUCAULT, 2013). Assim, considerando o discurso como um instrumento de poder, podese dizer que é uma formação de compromisso resultante da transação entre o interesse expresso e a censura inerente às relações de produção linguísticas que se impõem a um locutor dotado de uma competência determinada, isto é, de um poder simbólico sobre essas relações de produção (BOURDIEU \& MICELI, 1974). È assim através do discurso que a ideologia de poder é naturalizada.

\section{Discurso e Conversação Mediados pelo Computador}

Susan Herring (2008) diz que o discurso mediado pelo computador não garante uma interação necessariamente democrática. Arranjos sociais preexistentes (como o da nossa cultura patriarcal, por exemplo) são transferidos para o ciberespaço e criam condições de concorrência desiguais. Segundo Bernardes (2014), as tecnologias digitais revitalizaram as formas de participação e as possibilidades de interação, transformando as fronteiras das esferas pública e privada. Da mesma forma, possibilitaram a criação de espaços de apropriação de conteúdos, de geração ou multiplicação de acontecimentos, construídos dentro ou fora das redes, mas que geram desdobramentos e ressignificações variados nesses ciberespaços. Nesse sentido, para Buzato e Severo (2010), as pessoas enxergam na Internet uma possibilidade de resistir ao poder, apresentando os temas de discussão de forma emancipatória, libertária e democrática, como se o poder pudesse ser driblado. "Tem-se, com isso, um mascaramento dos efeitos do poder que operam, entre outros, produzindo discursos verdadeiros sobre modos de ser, concepções de mundo ou formas de se relacionar, sem que tais discursos sejam problematizados" (BUZATO \& SEVERO, 2010, p.06).

Diante desse cenário, e em confluência com as potencialidades comunicativas da era digital, o feminismo identifica, no ambiente virtual, um lugar de práticas e expressões coletivas, com novas significações e endereçamentos variados (TOMAZETTI, 2015). O movimento iniciou nos anos 1990 um esforço de criar espaços alternativos de visibilidade, em que as mulheres pudessem protagonizar posicionamentos ao assumirem o papel de autoras, produtoras e transmissoras de conteúdo, e hoje diversos grupos feministas se posicionam no terreno comunicativo da Internet (TOMAZETTI, 2015), reivindicado oficialmente pela primeira vez no Simpósio Internacional sobre a mulher e os meios de comunicação, organizado pela UNESCO, em Toronto, no Canadá, em 1995 (TOMAZETTI, 2015). A presença do feminismo na Internet posiciona o movimento em um ciclo de novas oportunidades alavancadas pela construção de laços solidários entre mulheres e feminismos de todo o mundo. De acordo com Ureta (apud TOMAZETTI, 2015), o espaço social e virtual dinamizado pelas redes sociais 
digitais proporcionou experiências de ativismo mais livres e acentuou as possibilidades de desenvolvimento de outros canais de comunicação e de trocas de informação.

Com as tecnologias da comunicação e da informação, as interações sociais encontraram novos ambientes para serem desenvolvidas, caracterizando sistemas interativos próprios, como, por exemplo, os sites de redes sociais. Segundo Rebs e Zago (2011) esses sistemas interativos são auto-organizáveis e auto-configuráveis, não apenas por máquinas que estabelecem e mantêm a conexão entre os usuários, como também pelos atores que ali estão interagindo. Embora a conversação seja compreendida como um fenômeno falado oral, a apropriação das ferramentas textuais da mediação do computador indica uma simulação de uma conversação (RECUERO, 2014). De acordo com Schinestsck (2015), a Comunicação Mediada pelo Computador (CMC) é muito mais do que uma simples conversa dada a partir da mediação de uma ferramenta tecnológica. Para ela, a CMC tem se mostrado como um meio alternativo de expressar valores e crenças coletivas que nem sempre se manifestam fora do contexto digital. Recuero (2012), por sua vez, diz que a CMC não é apenas influenciada pelas suas ferramentas, mas constitui igualmente um produto social.

Para Recuero (2011), a partir do início do século passado, os pesquisadores passam a dedicar seus esforços para entender esses fenômenos como constituídos pelas interações entre as partes. Esse olhar sistêmico fez-se necessário para entender não apenas as partes, mas as partes em interação, segundo a autora, para a qual a força dessa abordagem de estudos em redes está na necessidade de uma construção empírica que busque, a partir da observação sistemática, identificar padrões e teorizar sobre eles. Logo, estudar redes sociais é estudar os padrões de conexões expressos no ciberespaço. As redes sociais em sua representação no ciberespaço são diferentes das redes sociais no espaço off-line, tanto porque as conversações e as trocas sociais deixam rastros no ambiente online como porque a própria representação do grupo social no ciberespaço altera o grupo em si. Essas redes são representadas principalmente através dos sites de rede social e de outras ferramentas que permitem sua apropriação desse modo (RECUERO, 2014).

Os sites de redes sociais têm tido um impacto profundo no cotidiano das pessoas, alterando a forma como se relacionam, constroem e percebem valores e mesmo como constroem significados e sentidos. Eles não apenas refletem as redes, mas influenciam sua construção e, com isso, os fluxos de informação que circulam nesses grupos (RECUERO, 2012). Os dados que reunimos refletem a potência do site de rede social Facebook no Brasil. No início de 2016, 8 em cada 10 usuários estavam conectados à rede social. O site é acessado por 1 bilhão de brasileiros todos os dias. O Facebook, assim como outros sites de rede social, conforme Recuero (2014), é uma ferramenta apropriada simbolicamente para construir o 
espaço social no cotidiano dos atores, gerando práticas e ressignificando seus usos, no ciberespaço e na vida diária.

\section{Metodologia}

Para investigar os discursos neste ambiente digital, recorremos a aportes teóricos e metodológicos da Análise do Discurso Mediada por Computador (CMDA), desenvolvidos por Herring (2001, 2004), a fim de identificar padrões capazes de indicar a presença de discussões sobre o empoderamento feminino, bem como identificar outros padrões recorrentes de discurso no ambiente digital. Os pressupostos teóricos subjacentes à CMDA, propostos por Herring (2004), são aqueles da análise linguística do discurso, em sentido lato. Em primeiro lugar, supõe-se que o discurso exibe padrões recorrentes. Um objetivo primordial da análise do discurso é o de identificar padrões, mas que podem não ser óbvios para o observador casual ou para os próprios participantes do discurso. Em segundo lugar, supõese que o discurso envolve escolhas. Estas escolhas não são condicionadas por considerações puramente linguísticas, mas refletem fatores cognitivos e sociais. Desta forma, segundo Herring, a análise do discurso pode fornecer informações sobre fenômenos não-linguísticos, assim como linguísticos.

Herring parte dos níveis de linguagem e os distribui em quatro domínios, a saber: estrutura; sentido (significado); interação e comportamento social. A estrutura são as formações de palavras, expressões e estruturas de frases. O sentido corresponde aos atos de fala, locuções e sentidos de palavras. A interação diz respeito às trocas conversacionais, turnos, sequenciamentos e reciprocidade, e, o comportamento social, ao gerenciamento de face, discurso, negociações de conflitos, além da frequência e duração de mensagens enviadas e recebidas. A interpretação desses níveis é feita de acordo com a análise pelo pesquisador, feita a partir das questões propostas, dos dados coletados (HERING, 2004).

Para este estudo, fez-se uma seleção de postagens por recortes de tempo em dados coletados na página de fãs do Facebook oficial do filme Mulher-Maravilha, chamada "MulherMaravilha ". Quatro publicações (e comentários) em quatro recortes de tempo foram analisados, a saber: 1) um post na $2^{\mathrm{a}}$ semana que antecede o lançamento do filme (de 14 a 20 de maio de 2017); 2) um post na $1^{\text {a }}$ semana que antecede o lançamento do filme (de 21 a 27 de maio de 2017); 3) um post na semana do lançamento do filme (de 28 de maio a 03 de junho de 2017); e 4) um post na $1^{\text {a }}$ semana que sucede ao lançamento do filme (de 04 a 10 de junho de 2017), doravante chamados posts 1, 2, 3 e 4 respectivamente. 
Os posts analisados foram selecionados por terem sido os mais curtidos em cada uma das semanas citadas. Além disso, comentários dessas publicações também foram analisados, sendo escolhidos os sete comentários que mais receberam interações nessas postagens (conforme algoritmo do Facebook).

\section{Resultados e Discussão}

No estudo aqui relatado, foram analisadas quatro publicações, com sete comentários cada. Consideraram-se tanto as postagens como os comentários para analisá-los de acordo com as quatro categorias propostas por Herring, que, como vimos, são: estrutura, sentido, interação e comportamento social.

Quanto à Estrutura, ficou clara a intenção de levar o leitor a assistir o filme, na medida em que em todos os posts houve a presença de orientação para compra de ingressos para o cinema. Os posts analisados foram bastante parecidos, contendo basicamente as mesmas características. O uso da hashtag \#MulherMaravilha nos 4 posts analisados dá destaque à personagem e facilita a busca por indexação. Em todos os posts houve a presença de temporalidade, criando um senso de emergência. No post 1, foram utilizadas expressões como "Assista AGORA...", "Estreia $1^{\circ}$ de junho..." e "... a partir de 18 de maio.", No post 2, houve a expressão "Dia $1^{\circ}$ de junho...". Além disso, na imagem do post continha o texto "5 dias" indicando o tempo que faltava para a estreia do filme. No post 3 as expressões "...chega HOJE aos cinemas" e "Compre seu ingresso agora...". E no post 4, o trecho "Assista HOJE...".

No que se refere ao Sentido, identifica-se o propósito de divulgar o filme, tanto nas postagens como nos comentários. Poucos comentários abordaram o empoderamento feminino e apenas um trouxe à tona de forma direta questões do movimento feminista. No entanto, outros canais de comunicação com páginas temáticas sobre feminismo no Facebook e canais de sites de notícias abordaram o tema do feminismo mais diretamente, questionando e criticando a potencialidade da obra e da personagem para efetivamente posicionar as mulheres de forma empoderada em vez de simplesmente manter o status quo.

Ainda quanto ao Sentido, houve um ponto que chamou a atenção: a relação do empoderamento com a beleza física da atriz. Tanto na página Mulher-Maravilha como em outras páginas de Facebook, a discussão sobre os atributos físicos da personagem foi trazida à tona. É interessante identificar que as questões feministas, inevitavelmente, abordam a aparência das mulheres. Fica evidente a pressão social sobre a aparência da mulher e os padrões de beleza impostos em nossa cultura, como pudemos identificar. Os dados coletados apontaram para uma análise voltada à objetificação da mulher, ou, mais especificamente, aos padrões de beleza impostos às mulheres e sua relação com o empoderamento feminino. A 
preocupação com a aparência da Mulher-Maravilha, vista em comentários da página MulherMaravilha -- em que apontam a cor dos olhos da atriz, afirmam que a atriz estava "lacrando" e que seria "perfeita", ou ainda em comentários sobre a aparência das mulheres feministas, indicou ser essa, se não uma regularidade, ao menos uma constante..

Para os comentaristas analisados no estudo, o "ser linda" estava associado ao "ser poderosa". Elogios à aparência da personagem remeteram a esta conclusão quando afirmaram que ela é "linda e forte", por exemplo. Nesse sentido, Lourenço, Artemenko e Bragaglia (2014) afirmam que a propagação de estereótipos de gênero que objetificam a mulher frente ao gênero masculino ocorre também no meio midiático. As autoras reforçam que, assim como acontecia na publicidade de antigamente, ainda nos tempos atuais os meios de comunicação têm contribuído para perpetuar estereótipos de gênero. De fato, parece haver não só o reforço destes como sua ampla aceitação pelo público. Neste sentido, assim como Andrade (2012), percebemos que a figura de uma super-heroína mulher é constituída a partir de um modelo masculino opressor. Andrade diz que o que fugisse disso ameaçaria o masculino. Exemplos claros de medo frente à ameaça de uma Mulher-Maravilha fora dos estereótipos de beleza são os comentários que dizem “...no lugar da maravilhosa Gal Gadot colocasse uma gorda escrota com sovaco cabeludo..." e "não precisa deixar os pelos do suvaco crescer, ou enfiar cruz no rabo, nem pedir extinção dos homens...". De acordo com Mageste; Melo e Ckagnazzaroff (2008), existe uma confusão geral e certa ansiedade dos homens com respeito ao empoderamento feminino, uma vez que, para muitos, uma mulher empoderada os desempoderaria. Além disso, cabe ressaltar que nem sempre a relação entre discurso e poder é perceptível, mas o discurso funciona pulverizadamente em toda a extensão social como efeitos de poder, segundo Foucault (2013). Para entender a lógica da relação entre os saberes e o poder, é preciso considerar o fato de que a produção dos discursos é controlada por uma série de mecanismos de poder, de controle, seleção, organização e redistribuição, a fim de suavizar sua carga e dissipar-lhe o perigo de sua produção (FOUCAULT, 2013). Conforme Viana (2009), o discurso é não só limitado por quem detém o poder, mas é também reprodutor deste poder e é uma de suas formas de manifestação. A presença do referido estereótipo reflete a ambivalência que essa relação discurso-poder cria.

Quanto à Interação, observou-se que foi praticamente inexistente. No post 2, todas as comentaristas marcaram, através de recurso do Facebook, um ou mais contatos para sinalizar as pessoas marcadas - o que indica a intenção de interação com pessoas que estavam fora da postagem. Tais interações ocorreram na publicação que descrevia o tempo que faltava para a estreia. Observa-se, assim, a grande expectativa pela ida ao cinema que o post provocou. Mas em nenhum post analisado houve a intenção de provocar interação ou relacionamento, enfim, de pedir uma réplica. 
Por fim, no que se refere ao Comportamento Social, alguns comentários buscaram demonstrar autoridade, influenciar as pessoas para irem assistir ou não o filme através de expressões linguísticas de status, como, no post 2 , os seguintes trechos de comentários “... eu tô saindo com vc ou sem vc...”, “...deveríamos assistir mesmo mortas...”, “...já achei um filme pra gente assistir...", “...já decidiram se vcs vão comigo? Se não, deixem o dinheiro da pipoca e o ingresso...", “...temos que correr pro cinema assistir...”. No post 3, também uma comentarista tenta influenciar quando diz "não percam" e outra diz "vão assistir", e em outro comentário o trecho "Vamos sabotar e não assistir esse filme...". No post 4, um usuário dá sua opinião sobre o filme e divulga sua crítica através de um link que direciona para um post de blog, na tentativa de influenciar as pessoas a acessarem sua opinião. Observa-se também algumas questões de identidade. No post 1 uma comentarista parece identificada com o empoderamento da personagem e questiona o poder masculino quando afirma "Aí sim eu concordo e aplaudo, investirem em heroínas que já existem ou mesmo criarem outras. E não trocarem nossos 'heróis' por mulheres". Ainda no post 1, duas comentaristas utilizavam na foto de perfil uma imagem da Mulher-Maravilha, identificadas com a heroína. No post 2 uma mulher que diz "...a nós mulheres que somos uma maravilha" parece estar identificada com o empoderamento da personagem. Há duas ocorrências de negociação de poder. Primeiro, no post 1 , um homem diz "...as amazonas também são seres humanos..." e o comentário de uma mulher em oposição diz “...é filha de Zeus, ou seja, uma deusa mesmo.”. Segundo, no post 3, um homem diz "...sem dinheiro do ingresso" e em oposição uma comentarista diz "...valeu cada centavo...". Em ambos os casos não houve interação direta, mas os comentários se opunham e pareciam buscar defender posicionamentos opostos. Nestes dois casos, o posicionamento contrário aconteceu por parte de comentaristas mulheres em oposição a comentaristas homens. Também nos dois casos, as mulheres lançaram-se em defesa às críticas proferidas pelos homens. O empoderamento da personagem e da atriz também ficou evidente. Trechos como "Gal lacrando como Mulher Maravilha", "Maior heroína", "Melhor heroína" estavam presentes nos comentários do post 3; e trechos como "Gal Gadot perfeita" e "Gal Gadot ficou perfeita" foram apresentados no post 4. Em oposição ao empoderamento dado à personagem e atriz, há no post 1 uma tentativa de desempoderar a atriz na medida em que se faz referência a seus aspectos físicos como sendo piores que os da personagem, com o trecho "Não superei a escolha dessa atriz. Mulher Maravilha sem aquele olho azul é difícil de encarar.".

A esta altura, é inevitável mencionar o texto de Adorno e Horkheimer (1985), Dialética do Esclarecimento. Os autores apresentam uma crítica à sociedade ocidental contemporânea. Para eles, o programa iluminista transformou o saber em algo objetivo e neutro e o controle sobre a natureza acaba sendo levado ao extremo através do desmonte dos mitos. Em tese, a destruição dos mitos traria liberdade e, pela superação da própria dominação, seria 
substituída pela razão do mercado. De fato, o controle sobre a natureza não foi apenas mantido, mas agravado pela dominação dos próprios homens, através das forças do mercado. Para os autores, as pessoas só encontram um lugar social quando se tornam consumidores. É o fetiche da igualdade, comum a todas as sociedades ocidentais, democráticas ou não, que torna o indivíduo genérico, impotente em uma sociedade dirigida pela coerção do mercado. $\mathrm{E}$, como correlato da coação atribuída à natureza não dominada, manifesta-se a mistificação das massas, promovida pelo esclarecimento que antes viria para impedi-la. Para Adorno e Horkheimer, o totalitarismo do mercado e da política é capaz de produzir o homogêneo com o suporte da mídia de massa, isto é, a indústria cultural. A indústria cultural é, para eles, um produtor de mercadorias impregnadas de conteúdos simbólicos, que promovem, ao mesmo tempo, relações materiais de produção e formas ideológicas de dominação. É o último elo da cadeia de sujeição e atua para que o sistema se perpetue. Prometendo liberdade, a indústria cultural estabeleceu novas formas de dominação, que tornam os seres humanos homogeneizados pelo mercado e sem espaço para a crítica.

E é esse o cenário em que o filme da Mulher-Maravilha foi criado. A personagem, em primeira instância, parece tentar quebrar o estereótipo de mulher donzela recatada, mas, na verdade, o filme é um produto de consumo e, assim, fortalece os padrões na medida em que a atriz que representa a personagem é exatamente o modelo de beleza exigido na nossa cultura atual. Houve, inclusive, um comentário que exigia ainda mais da atriz, que tivesse olhos azuis como sinal de beleza. Desse modo, a noção de beleza está diretamente relacionada à de empoderamento, na medida em que, para as próprias mulheres, inseridas na indústria da cultura, a aparência, definida pela beleza e poder de atração, definem o valor próprio (SHAW, 2003). Como vimos no estudo, mesmo mulheres relacionam o poder da personagem com sua beleza física.

Lopes (2009) afirma que, em uma cultura hegemônica, há indicativos de resistência como forma de performar contra um modelo de imposição cultural vigente. Mais especificamente, a autora discute a obra de George Yúdice, intitulada A conveniência da cultura: usos da cultura na era global, e afirma que a cultura é hoje um recurso que gera e atrai investimentos, Lopes diz que a concepção de "cultura como recurso" é tomada por Yúdice desde a absorção da ideologia e da sociedade disciplinar pela racionalidade econômica e ecológica, na contemporaneidade. Inserida no movimento global das indústrias culturais, que discursam pela preservação das tradições como forma de manter a biodiversidade, a cultura conteria e expressaria elementos importantes para os agenciamentos da sociedade civil, visando o desenvolvimento político e econômico. As diferenças são vendidas como produtos culturais, em alguns casos como exotismo, mas a administração das massas pelos padrões estereotipados não só se mantém (como no caso 
do padrão de beleza em que a atriz se enquadra), como é usada para criar produtos (como o próprio filme em si). Através da ampla difusão da tecnologia e do acesso à Internet, os atores culturais desenvolvem uma economia das experiências, encenando e desempenhando as normas sociais, ou criticando-as.

Para Yúdice, o uso da tecnologia se apresenta como um apelo que agrupa e ordena, revelando uma verdade que bloqueia outras verdades. Daí que a reflexão sobre a tecnologia deve considerar, simultaneamente, a familiaridade com a essência normativa e suas diferenças. Atuando na contramão dos produtos gerenciados pela hegemonia cultural, surgem o que Yudice chama de sujeitos performativos subversivos que, indo além da negociação da agência cultural, posicionam-se de forma rival à alteridade das normas globais. Lopes explica que no interior do campo de forças performativas emergem interpretações rivais que buscam desconstruir o modelo totalizador, onde os atores agenciam sua autonomia e legitimidade em modalidades alternativas de poder, enquadrando interpretações que canalizam a significação dos seus discursos e atos.

Desse modo, assim como temos a beleza padrão como objeto de status social e de poder, temos forças contrárias à hegemonia cultural assim estabelecida. A luta das mulheres pelo empoderamento feminino aparece como força contrária à hegemonia masculina, mas muitas vezes, no íntimo, atua a favor, como no caso da personagem Mulher-Maravilha e todo seu potencial de discussão sobre o feminino. Apesar de a personagem ter sido criada para representar uma mulher forte que defendesse questões feministas, a figura da MulherMaravilha em si é bastante controversa, uma vez que representa exatamente o estereótipo de mulher contra o qual o movimento feminista luta: uma mulher branca e de proporções físicas inatingíveis. Tanto é que o filme não demonstrou ter potencial para discussão das questões feministas nas redes sociais, como demonstram os dados do estudo.

A própria diretora do filme, Patty Jakens, se contradiz quando se refere ao potencial feminista da personagem. Ela declarou em entrevista para o site Omelete que a MulherMaravilha não é uma personagem feminista, ao mesmo tempo em que declarou em seu Twitter "[...]Mas se as mulheres sempre precisam ser difíceis, duronas e perturbadas para serem fortes, e não estamos livres para sermos multidimensionais ou celebrar um ícone para mulheres do mundo todo por ela ser atraente e amável, não chegamos muito longe, não é mesmo?[...]", referindo-se às críticas do diretor de cinema James Cameron, que disse em entrevista para o jornal The Guardian que o filme Mulher-Maravilha seria um retrocesso, pois se trataria de mais uma produção hollywoodiana predominantemente masculina. Ele afirmou que a personagem seria um ícone objetificado. Muitas são as críticas das mulheres à referência da personagem como representação de causas feministas. Por exemplo, na ocasião da nomeação da ONU que conferiu à personagem Mulher-Maravilha o título de 
Embaixadora Honorária pelo Empoderamento das Mulheres e Meninas, uma petição online arrecadou 45 mil assinaturas contrárias à nomeação. Na petição, ativistas feministas alegam que a sexualização explícita da personagem iria de encontro aos conceitos do empoderamento feminino e que uma personagem fictícia não seria a melhor escolha para a representação do empoderamento feminino. Declarações como "Uma mulher branca peituda de proporções impossíveis, seminua em um pequeno e justo macacão com uma bandeira americana" e "O empoderamento feminino é tão inacreditável que precisamos escolher uma personagem fictícia?" foram usadas como argumentos na petição. O resultado foi que a ONU voltou atrás e revogou o cargo apenas 2 meses depois, como noticiado no jornal The Guardian. Fica evidente, assim, o tamanho do embate que a personagem é capaz de promover quando se refere ao seu potencial de representar ou não o empoderamento feminino, seja em disputas de poder no contexto digital, no Cinema, ou em organizações mundiais. Tendo em vista o potencial para discussão sobre o empoderamento feminino, Maria Cecília, na dissertação, esperava encontrar um debate sobre gênero de maneira mais contundente.

No ambiente de cultura digital e, pontualmente, os sites de redes sociais, para Buzato e Severo (2010), o poder parece ter uma falsa ilusão de que pode ser driblado, uma vez que a Web 2.0 se trata de um espaço aberto e livre do controle das instâncias jurídicas ou políticas. Em princípio, identifica-se neste contexto, a sensação de se tratar de um espaço público, emancipatório e democrático, livre das malhas do poder. Porém, na verdade, para os autores, esta sensação "é só mais um efeito do funcionamento do poder, que, para ser tolerável, cria a ilusão de que a (aparente) ausência de um poder-jurídico implicaria um espaço de liberdade" (2010, p.11).

Assim, os autores afirmam que os pressupostos que fazem a Web 2.0 funcionar são políticos, na medida em que incitam a circulação e a proliferação de discursos e informações; registram os movimentos e dados dos usuários; produzem saberes e verdades que direcionam desejos e modos de ser; ao mesmo tempo que produz a sensação de ser vigiado e a possibilidade de vigilância lateral contínua. O que os autores postulam, não é que a Internet não tenha vocações libertárias, mas que o funcionamento e circulação do poder acontece exatamente quando os sujeitos podem agir livremente. Destacam, ainda, o fato de que há um complexo jogo de resistência e vigilância, em que a liberdade está permeada de práticas não-discursivas e discursivas que se impõem aos sujeitos ao levá-los a ser "rastreados, calculados, hierarquizados e tornados mercadoria" (p.12). O que se vê, então, é uma outra forma de subjetivação, resistência e um novo olhar sobre os espaços de liberdade. Neste sentido, recorremos à reflexão de que, muitas vezes, discursos feministas de empoderamento estão, de fato, a serviço da cultura capitalista machista, que "vende" o 
feminismo como mercadoria. Nesse sentido, também o filme Mulher-Maravilha pode estar a serviço desse jogo de poder, o que, se reforça o patriarcado, nem por isso deixa de servir para empoderar mulheres. Assim os discursos de empoderamento que envolvem a personagem Mulher-Maravilha estão vinculados com discursos de uma indústria cultural cruel e machista na qual a disputa de poder está exposta. Os movimentos de resistência feminista, apesar de submetidos ao patriarcado, fazem parte desse novo cenário de liberdade, vislumbrado pelo contexto digital.

Os objetivos da pesquisa foram "identificar se e de que maneira discursos sobre a super-heroína Mulher-Maravilha se articulam com questões feministas" e "analisar se discursos sobre a Mulher-Maravilha têm relação com o empoderamento feminino" a partir do objetivo geral de "investigar discursos no Facebook acerca do lançamento do filme MulherMaravilha a fim de verificar a presença de questões feministas e quais são os temas debatidos", e, mais especificamente, "identificar se o filme mobiliza discursos sobre o empoderamento feminino." Vemos que, nos discursos sobre a super-heroína Mulhermaravilha, há uma tentativa de articulação com as questões feministas e que trazem à tona o debate sobre empoderamento feminino. Chama, contudo, a atenção o fato de que o empoderamento feminino esteja relacionado aos atributos físicos da personagem. Os aspectos da beleza da atriz foram destacados como modo de ressaltar o empoderamento da heroína. Uma mulher bela, de acordo com um dado padrão, parece ser a única mulher possível de ser empoderada - o que perpetua os estereótipos socialmente aceitos de mulher.

Os discursos de empoderamento feminino passam inevitavelmente por critérios preestabelecidos e impõe uma imagem idealizada de mulher. Este fato vem a consolidar valores implícitos de nossa sociedade de que uma mulher forte é uma mulher bela. $E$ as relações de poder impostas pelo patriarcado são identificadas mesmo num contexto de uma mulher figurando o heroísmo, mesmo em um ambiente democrático, como o Facebook. Já nas páginas de fãs direcionadas para o debate das questões de gênero, o empoderamento feminino apareceu de modo muito mais contundente. O que limita a discussão.

Mesmo um filme altamente popular, com uma personagem notoriamente feminista, não foi capaz de suscitar discursos de empoderamento feminino de forma enfática, como Maria Cecília esperava. Não é fácil quebrar os paradigmas, especialmente com suporte da mídia, especialmente quando a mulher é o produto, e não o sujeito. Superar as questões normativas impostas culturalmente à mulher continua sendo um desafio para homens e mulheres que buscam uma sociedade mais justa. As mulheres passaram a ocupar os espaços cibernéticos com o intuito de veicular discursos de empoderamento e desnaturalizar 0 patriarcado, mas ao invés disso, reforçam crenças culturalmente aceitas em nossa sociedade. Assim, como o estudo permite dizer, para desnaturalizar os discursos que legitimam as 
práticas simbólicas de poder do masculino normativo típico sobre o feminino é preciso, primeiro, uma tomada de consciência da opressão, um exercício que deve ser praticado diariamente nos debates sobre gênero, seja nos sites de redes sociais ou em outros ambientes e seja nos espaços designados à discussão de gênero, ou não. A verdadeira liberdade das mulheres reside em elas serem o que quiserem ser. Mas será que elas conseguem identificar o que realmente querem, ou o que podem querer, ser? Será que seu querer não depende de normatividades sutis que as afetam sem que elas percebam? Essas e outras questões podem ser uma motivação para novos estudos. Elas surgem das ambivalências que o estudo conseguiu identificar.

\section{REFERÊNCIAS}

ADORNO, Theodor. Dialética do esclarecimento. Zahar, 1985.

BERNARDES, Márcia. Uma reflexão inicial sobre feminismo na internet: gênero e corpo. 2014. BOURDIEU, Pierre; MICELI, Sergio. A economia das trocas simbólicas. São Paulo: Perspectiva, 1974.

BOURDIEU, Pierre. The forms of capital.(1986). Cultural theory: An anthology, v. 1, p. 81-93, 2011. Disponível em: <https://faculty.georgetown.edu/irvinem/theory/Bourdieu-Forms-ofCapital.pdf>. Acesso em out. 2017

. O poder simbólico. Rio de Janeiro: Bertrand Brasil, 1989. 311p.

. A economia das trocas linguísticas. São Paulo: Edusp, p. 116, 1996.

BUZATO, Marcelo El Khouri; SEVERO, Cristine Gorski. Apontamentos para uma análise do poder em práticas discursivas e não-discursivas na WEB 2.0. Encontro do Círculo de Estudos Linguísticos DO SUL, v. 9, 2010.

COSTA, A. A. O movimento feminista no Brasil: dinâmicas de uma intervenção política. Revista Gênero, v. 5, n. 2, 2013. Disponível em: https://pactoglobalcreapr.files.wordpress.com/2012/02/5-empoderamento-ana-alice.pdf Acesso em 08 jun. 2017

DOMINGOS, J. J. Discurso, poder e subjetivação. Uma discussão foucaultiana. 3ª Ed. João Pessoa: Marca de Fantasia, 2015.

FOUCAULT, Michel. A ordem do discurso. Tradução de Laura Fraga de Almeida Sampaio, v. 3, p. 49, 2013.

HERRING, Susan C. (2001) Computer-mediated discourse. In: D. Schiffrin, D. Tannen, \& H. Hamilton (Eds.), The Handbook of Discourse Analysis (pp. 612-634). Oxford: Blackwell 
Publishers. Disponível em: <http://ella.slis.indiana.edu/ herring/cmd.pdf> Acesso: em 01 ago. 2016

. (2004) Computer-Mediated Discourse Analysis: An aproach to researching online behavior. In: BARAB, S. A., KLING, R., \& GRAY, J. H. (Eds.). Designing for Virtual Communities in the Service of Learning (pp. 338-376). New York: Cambridge University Press. . Language and the Internet. The International Encyclopedia of Communication, 2008.

LOPES LOURO, G. Cinema e Sexualidade. Educação \& Realidade, 33 (1), 81-97, 2008. LOURENÇO, Ana Carolina Silva; ARTEMENKO, Natália Pereira; BRAGAGLIA, Ana Paula. A "objetificação" feminina na publicidade: uma discussão sob a ótica dos estereótipos. In: Congresso de Ciências da Comunicação na Região Sudeste Intercom Sudeste. São Paulo: Intercom. 2014. p. 1-15.

MAGESTE, Gizelle de Souza; MELO, Mcol; CKAGNAZAROFF, Ivan Beck. Empoderamento de Mulheres: uma proposta de análise para organizações. Encontro de Estudos Organizacionais da Associação Nacional de Pós-Graduação Em Administração, V, Belo Horizonte, 2008.

PINTO, Céli Regina J. Feminismo, História e Poder. Rev. Sociol. Polít., Curitiba, v. 18, n. 36, p. $15-23$, jun. 2010

REBS, Rebeca Recuero; DA SILVA ZAGO, Gabriela. As potenciais formas de interações em ambientes virtuais. Observatorio (OBS*), v. 5, n. 3, 2011.

RECUERO, R. Linguagem e Comunicação no IRC, 2001. Disponível em: <http://www.raquelrecuero.com/intercom.htm> Acesso em: out. 2017

Redes sociais na internet, difusão de informação e jornalismo: elementos para discussão. Metamorfoses jornalísticas, v. 2, p. 1-269, 2009. Disponível em: <http://www.pontomidia.com.br/raquel/artigos/artigoredesjornalismorecuero.pdf> Acesso em: out. 2017

Redes sociais na internet. $2^{\underline{a}}$ edição. Porto Alegre: Sulina, 2011.

A conversação como apropriação na comunicação mediada pelo computador.

Comunicação, cultura de rede e jornalismo, p. 259-274, 2012.

. Curtir, compartilhar, comentar: trabalho de face, conversação e redes sociais no Facebook. Verso e Reverso, v. 28, n. 68, p. 117-127, 2014.

SAFFIOTI, Heleieth IB. Contribuições feministas para o estudo da violência de gênero. Cadernos pagu, n. 16, p. 115-136, 2001.

SCHINESTSCK, Letícia Ribeiro et al. " Se a carapuça serviu..." estudo de caso sobre a cultura das indiretas e a violência simbólica no Facebook. Dissertação de Mestrado. Universidade Católica de Pelotas, 2015.

SHAW, I. S. O corpo feminino na propaganda. In: BERNADETTE, L.; SANTANA, G. (Org.). 
Corpo e mídia. São Paulo: Arte \& Ciência, 2003. p. 193-206.

TOMAZETTI, Tainan Pauli. O feminismo na era digital e a (re) configuração de um contexto comunicativo para políticas de gênero. Razón y palabra, n. 90, p. 39, 2015.

VIANA, Nildo. Linguagem discurso e poder: ensaios sobre linguagem e sociedade. Virtual books, 2009. 